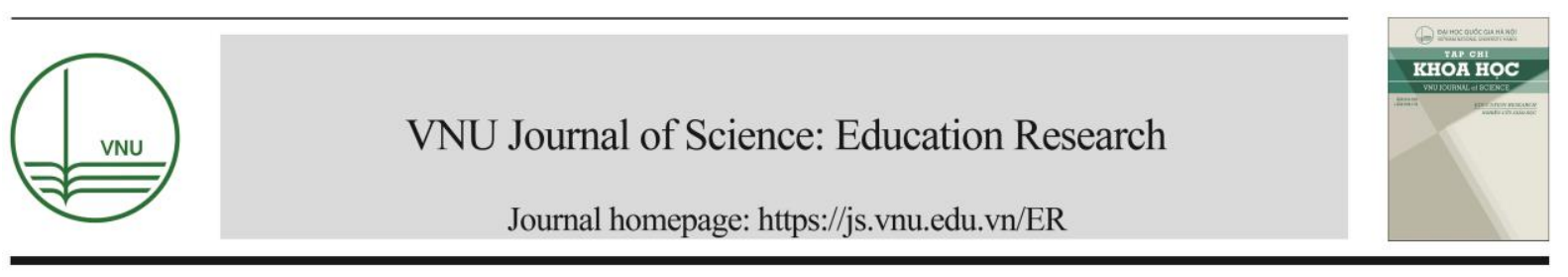

Original Article

\title{
Assessing the Effectiveness of Teachers' Mental Health Literacy Training in Cambodia: A Randomized Controlled Trial
}

\author{
Bunna Phoeun ${ }^{1,3, *}$, Amanda J. Nguyen², Dang Hoang Minh ${ }^{3}$, \\ Tran Thanh $\mathrm{Nam}^{3}$, Bahr Weiss ${ }^{4}$ \\ ${ }^{1}$ National Institute of Physical Education and Sport, Ministry of Education Youth and Sport, Cambodia \\ ${ }^{2}$ University of Virginia, YouthNex, Curry School of Education and Human Development, \\ PO Box 400281, 417 Emmet St South, Charlottesville, Virginia, 22904, USA \\ ${ }^{3}$ VNU University of Education, 144 Xuan Thuy, Cau Giay, Hanoi, Vietnam \\ ${ }^{4}$ Vanderbilt University, Department of Psychology and Human Development, Peabody College, \\ 230 Appleton Place, Nashville, TN 37203 USA \\ Received 11 August 2019 \\ Revised 23 September 2019; Accepted 23 September 2019
}

\begin{abstract}
School-based mental health literacy (MHL) programs are used to reduce stigma and promote help-seeking among students and teachers. This study aimed to adapt and evaluate a teacher-delivered MHL program in Cambodia, where the impact of MHL programs has not previously been evaluated. 67 teachers and 275 students from a high school in Phnom Penh voluntarily completed the study. School staff were randomly assigned, and classrooms purposively assigned, to either a 2-day MHL training program or a control condition. Four teachers in the intervention condition were also pragmatically selected to deliver a 6-week classroom MHL curriculum to students; these teachers receive an extra day of implementation training. Teacher and student MHL were assessed before and after the intervention. Results showed significant improvements in all indicators of teacher and student knowledge and attitudes about mental illness; largest improvements were in teachers' perceptions of dangerousness and willingness to interact. This pilot RCT supports the potential benefits of school-based MHL training in Cambodia, where there is substantial mental health stigma and discrimination. However, small to moderate effect sizes, particularly for students outcomes, suggest a need for further refinement and testing of the curriculum to optimize impact, including further consideration of implementation strategies and supports.
\end{abstract}

Keywords: Adolescents, program effectiveness, mental health literacy, stigma, school-based.

\footnotetext{
${ }^{*}$ Corresponding author.

E-mail address: bunnapsyeng@gmail.com

https://doi.org/10.25073/2588-1159/vnuer.4279
} 


\section{Introduction}

Child mental health problems are common worldwide, with up to $20 \%$ of children being affected each year [1]. Untreated child mental health conditions severely influence children's development, educational attainments, and their potential to live fulfilling and productive lives $[2,3]$. Given the high burden of these common conditions, promoting positive mental health and wellbeing throughout development has been recognized as a grand challenge [4] and integrated into the UN sustainable development goals [5].

Supporting child mental health is particularly challenging in many low - and middle-income countries (LMIC), where mental health service systems struggle due to lack of human, financial, political, and infrastructure resources and supports [6-12]. People living in LMIC also tend to have lower levels of knowledge and understanding of mental health problems as medical issues and higher levels of mental health-related stigma, which can become a barrier to seeking or offering help [13].

In Cambodia, a largely agricultural country in Southeast Asia, the situation is consistent with the general trends described above. Cambodia is home to largest youth and adolescent population in the South East Asia region, with approximately two third of population between age of 15-24 and nearly a quarter between 10-19 year old [14]. Previous studies suggested a high prevalence of mental health-related problems among both Cambodian children and adults [15-17]. In a nationally representative study, $8.2 \%$ of households with children reported one or more children were having school problems, $11.5 \%$ reported child aggressive behavior, and $4.9 \%$ reported children were experiencing other mental health-related problems [15]. With a focus on school problems and externalizing behaviors, these caregiver-reported statistics likely underestimate the full burden of disorder. And yet there remain multiple barriers to child mental health care, including shortages of human resources, mental health budget, and infrastructure, as well as low mental health awareness within the community $[18,19]$.

Increasing school capacity to identify and respond to child mental health needs is a logical approach to addressing the mental health treatment gap in LMIC, given that most children spend a significant portion of their day in schools [20-24]. Teachers can promote student mental health by providing psychologically supportive classrooms; are often the first adult to identify children's mental health needs and make referrals for services; and are a key mechanism for implementation of classroom mental health programs [25]. The role of educators in the recognition and promotion of early mental health education and intervention has been promoted in a range of other LMICs, such as neighboring Vietnam [26]. This is a natural fit in Cambodia, where participation in the educational system is high; $87.3 \%$ of children attend primary school (grades 1-6), 43.5\% attend lower secondary (grades 7-9) and 21.6\% attend upper secondary (grades 10-12) [27, 28].

To harness their potential to provide mental health support to students, teachers' mental health literacy is crucial. Jorm [29] defines mental health literacy as "knowledge and beliefs about mental disorders and their treatment, which aid their recognition, management or prevention" (p.396). Mental health literacy has several components, including (1) understanding how to maintain positive mental health, (2) understanding mental disorders and their treatments, (3) low levels of stigma related to mental disorders, and (4) high levels of mental health-related helpseeking efficacy [30].

As is the case in many LMIC [31, 32], low mental health literacy has been identified as a challenge in Cambodia [33]. Khmer cultural explanations for mental illness originate from Buddhist-Hindu beliefs, beliefs in spirits, luck and astrology, and emphasis on the connection between physical and mental health; help-seeking through the medical system often 
only occurs when traditional methods are unsuccessful in addressing the problem [34]. Therefore, efforts to leverage school-based mental supports must include effective, school-based resources to increase mental health literacy. However, two recent reviews of school-based mental health literacy studies found relatively few studies in LMIC and none in Cambodia $[34,35]$. Country-specific research is necessary to account for factors, such as cultural beliefs and education system structures, that could potentially influence the acceptability and effectiveness of programs [36, 37].

Current Study

The goal of this study was to evaluate a culturally adapted version of a school-based mental health literacy program, initially developed in Canada, for use in Cambodian high schools. Specifically, we aimed to adapt the program, evaluate baseline mental health literacy of both teachers and students, and compare post-intervention mental health literacy scores between teachers and students who were randomized to the intervention vs. control condition. We hypothesized that intervention participation would result in higher mental health literacy among both teachers and students.

\section{Methods}

\subsection{Setting}

Our study was carried out in one private school in Phnom Penh capital city of Cambodia. The selection of a private school was due to the nature of the educational system in Cambodia that would have required permission from the Minister of Education to conduct a study in the public school system. This school offers a general education program from preschool to high school, with a total population of approximately 1300 students (approximately 500 at the high school level) and 108 staff.

\subsection{Study Design}

We used a pre-post, randomized controlled trial design. School staff were individually randomized to either the MHL intervention group or a no-intervention control group. To avoid contamination, 7th and 11th grade classrooms were purposively assigned to receive the classroom MHL curriculum while students in 8th and 10th grades received standard (non-intervention) coursework. The study was approved by the Cambodian National Ethics Committee for Health Research, Ministry of Health (No. 055NECHR).

\subsection{Intervention}

The Mental Health \& High School Curriculum Guide[38] is an evidence-based mental health literacy training program originally developed in Canada (www.teenmentalhealth.org). The Guide includes a teacher preparation component as well as a classroom curriculum. It includes six modules: (1) The Stigma of Mental Illness; (2) Understanding Mental Health and Mental Illness; (3) Information on Specific Mental Illnesses; (4) Experiences of Mental Illness; (5) Seeking Help and Finding Support; and (6) The Importance of Positive Mental Health. Prior research in Canada as well as other LMIC suggests positive program impacts, but typically has not included a control condition for comparison [39-43].

The USA Edition: Washington State, 2nd Edition version of the Guide [38] was adapted and translated into Khmer language by the lead author (BP). The adapted materials were then reviewed by a team of bilingual Cambodian psychologists. Suggested adaptations included replacement with more appropriate Khmer words and expressions (e.g., for "mental illness" and "mental health problems"). As this study was aligned with a similar study being undertaken in Vietnam, adaptations made for that context were also incorporated into the Cambodian study. This included a structural 
change to present depression first rather than schizophrenia. The rationale for this change was that teachers would more frequently encounter students with depression than schizophrenia, and common perceptions of mental illness as "madness" or "craziness" would be reinforced if the first mental illness presented was schizophrenia.

In the standard implementation of this program, all teachers receive a 3-day teacher preparation training that includes two days of training focused on improving teacher MHL, and a third day of "train the trainer" training focused on preparing teachers to deliver the classroom curriculum. In the current study, this approach was modified to include both teaching and non-teaching staff and to accommodate a within-school study design that included a control comparison group at both the staff and student level. All staff randomly assigned to the intervention condition received the 2-day training program focused on building MHL. Four teachers in the intervention condition were also pragmatically selected to subsequently deliver the classroom-based curriculum, and therefore also received the 3rd day of training in methods for teaching the curriculum in their classroom. Teacher selection for this role was non-random, in consultation with the school director, because they taught English, Library, and Khmer language (i.e., classes in which the MHL materials could be included without deviating from governmental curriculum requirements).

After completing the training program, implementing teachers were given two weeks to review and prepare to deliver the classroom curriculum. Before beginning to implement the classroom curriculum, these four teachers participated in a consultation meeting with the researcher and two research assistants to review the classroom implementation plan and address any outstanding questions. These four teachers then implemented the MHL classroom curriculum in six weekly, 1-hour lessons in which each lesson focused on one of the six Guide modules. Control classrooms completed their standard, non-MHL coursework during this time.

\subsection{Sample}

A total of 100 staff were contacted for recruitment. $N=73$ (intervention: $n=36$; control: $n=37$ ) consented and returned the baseline assessment. Of those, 67 provided complete data for analysis (intervention: $n=34$, 94\%; control: $n=33,89 \%$ ); reasons for staff loss to follow up were unrelated to the project (e.g., change of employment). Of $N=307$ students $(98 \%$ of those contacted) who provided consent, 302 students provided T1 data (intervention: $n=158$; control: $n=144$ ), and 301 students provided $\mathrm{T} 2$ data (intervention: $n=157$; control: $n=144$ ). However, in some cases students provided inconsistent identifier data that precluded matching their records, resulting in a final sample size of 275 students (intervention: $n=145,92 \%$; control: $n=130,90 \%$ ) who provided complete data for analysis.

\subsection{Teacher Measures}

Teacher outcomes were assessed using the Mental Health Knowledge Quiz (MHL-Q), Mental Health Literacy Scale (MHLS), and Beliefs toward Mental Illness (BMI). These assessments were translated, adapted and also piloted with 10 staff before beginning the study.

The Mental Health Knowledge Quiz [38] is an assessment developed for use with the curriculum to assess knowledge of information presented in the guide. The quiz consists of 30 true/false items (e.g., "a phobia is an intense fear about something that might be harmful such as heights, snakes, etc."). Scores are reported as the proportion correct (range: 0-1), with higher scores indicate greater knowledge. Internal consistency was not calculated as these items are not intended to measure a single underlying construct.

The Mental Health Literacy Scale by O'Connor \& Casey [44] was used to assess teachers' knowledge and attitudes regarding mental health and related constructs. The 
original MHLS is a 35-item measure demonstrating good internal consistency $(\alpha=.87)$ and test-retest reliability $(r=.80)$, and support for its validity for use in evaluating outcomes of mental health literacy training programs [45]. Seven items were removed as not applicable to Cambodia, leaving a total of 28 items organized into four subscales: (1) ability to recognize mental disorders (e.g., "If someone experienced [symptom description], to what extent do you think it is likely they have [name of disorder]?"; eight items); (2) Mental health help-seeking/self-efficacy (e.g., I am confident that I know where to seek information about mental illness"; four items); (3) stigma/negative attitudes toward mental illness (e.g., "If I had a mental illness I would not tell anyone"; 9 items); and (4) willingness to interact with people with mental illness (e.g., "How willing would you be to have someone with a mental illness marry into your family?" 7 items). Items were evaluated using a 5-point Likert scale ranging from 0 to 4 . Scores were calculated as the mean of all answered items to account for missingness. Higher scores may be interpreted as more positive for all sub-scales except for stigma, in which higher scores indicate greater stigma. Internal consistency for the full scale was $\alpha=.61$ (T1) and $\alpha=.72$ (T2). For the subscales, internal consistency was: Recognition $\alpha=.60$ (T1) and $\alpha=.66$ (T2); Self-efficacy $\alpha=.63$ (T1) and $\alpha=.74$ (T2); Negative attitudes / stigma $\alpha=.60$ (T1) and $\alpha=.66$ (T2); and Willingness to interact $\alpha=.62$ and $\alpha=.79$ (T2).

Stigma was also measured using the Beliefs towards Mental Illness [46], a 21-item scale designed to assess negative stereotypical views of mental illness. Response options use a six-point Likert-scale ranging from 0 to 5 . Scores were calculated as the mean of all included items to account for missingness; high scores indicate more stigma negative attitudes toward mental illness. The items are organized into three subscales: (1) dangerousness (e.g., "a mental ill person is more likely to harm others than a normal person"; five items); (2) poor interpersonal/ social skills (e.g., "I am afraid of what my boss, friends would think if I were diagnosed as having a psychological disorder"; 10 items); and (3) Incurability (e.g., "Individuals diagnosed as mental ill will suffer from the symptoms throughout their life"; 6 items). Internal consistency for the full scale was $\alpha=.81$ (T1) and $\alpha=.87$ (T2). For the subscales, internal consistency was: Dangerousness $\alpha=.77$ (T1) and $\alpha=.84$ (T2); Poor social skills $\alpha=.53$ (T1) and $\alpha=.54$ (T2); and Incurability $\alpha=.54$ (T1) and $\alpha=.54$ (T2).

\subsection{Student measures}

Students completed the Mental Health Knowledge and Attitude Test [38], a 36-item questionnaire developed for use with the Guide. This measure includes a 28-item knowledge assessment (e.g., "People who have a mental illness are frequently violent"). Response options were true/false/I don't know; to avoid correct answers due to guessing, students were encouraged to select "I don't know" rather than guess if they did not know the answer. Knowledge scores are reported as the proportion correct (range : 0-1). The remaining eight items in the test assess stigma (e.g, "a mentally ill person should not be able to vote in an election"), with response options on a 7-point Likert scale ranging from 0 "strongly disagree" to 6 "strongly agree". Internal consistency was $\alpha=.47$ (T1) and $\alpha=.56$ (T2).

\section{Study procedures}

Study Recruitment. After receiving approval to conduct the study, the lead researcher approached teachers and school staff to introduce the study and obtain informed consent from participants. Informed consent at the student level was obtained through a passive consent process with a letter sent home to the parents, and with students given the option to opt out of data collection.

Intervention Allocation. Teachers were randomly assigned to the MHL program or control condition based on a number included on their consent form. As previously described, 
classroom-level allocation was purposive to avoid contamination while counterbalancing the two groups for developmental differences. Students in 7 th and 11th grade classrooms were assigned to receive the intervention, while students in 8th and 10th grade classrooms were assigned to the control condition. Students in grades 9 and 12 were not included in this study as they were preparing for examinations.

Teacher Training. The in-person staff training, including the 2-day training for all intervention staff and the additional 3rd day of training for the four implementing teachers, was led by the lead researcher. Staff in the control condition received no MHL training. Staff received the equivalent of $\$ 5$ USD for completing the baseline- and follow-up assessments, \$20 for participating in the 2-day training, and $\$ 35$ for delivering the classroom-based curriculum.

Classroom Implementation. The four implementing teachers taught The Guide MHL curriculum to 7 th and 11th grade classrooms during regular instructional time (i.e., when students would normally be studying Khmer, Library, or English). The six weekly, one-hour lessons were delivered over an 8-week period due to school holidays. Instruction was observed by two research assistants who also attended the teacher training workshop and received additional training in classroom observation to monitor teacher fidelity to the intervention materials. These research assistants were present for monitoring only; they were instructed not to provide any support to teachers or intervene the session. Their main role were only to observing the teacher delivering The Guide in the classroom by using the teacher fidelity rating checklist and to provide feedback their classroom observation to researcher.

\subsection{Data collection}

All instruments were administered at baseline (T1) and post-intervention (T2). Assessments were administered to both intervention and control groups on the same schedule. T1 assessments were administered before the beginning of the teacher training workshop for teachers, and before the beginning of the classroom implementation for students. T2 data collection for both teachers and students took place the week after completion of the full classroom delivery of the MHL curriculum.

\subsection{Data analysis}

Scale scores were calculated as the item mean. One-Way Analysis of Variance (ANOVA) was used to examine whether baseline mental health literacy scores varied by respondent demographics. For teachers, this included sex (male/female), education (high school education or less) and work experience (less than 5 years vs. 5 or more years). For students, we examined differences by sex and grade level.

Analysis of Covariance (ANCOVA) was used for both the teacher and student data using complete cases only. Models included T2 scores on the mental health literacy-related scales the dependent variables, baseline $\mathrm{T} 1$ scores as covariates, and Group (program, vs. no program) as the independent variable. In addition, paired (T1, T2) t-tests also were conducted to evaluate within-group change to determine whether between-group differences at $\mathrm{T} 2$ reflected improvements in the treatment group vs. worsening in the control group (or both).

\section{Results}

Staff participants were predominantly women $(79 \%)$, with a median age of 27 and a median of four years of teaching experience. Just over half had a bachelor $(53 \%)$ or masters (3\%) degree, while others had either a high school $(24 \%)$ or junior high school $(15 \%)$ education, and $5 \%$ did not disclose their education background. Two thirds were teaching staff $(66 \%)$, with others in administrative or other non-teaching roles. 
Students were $62 \%$ female with a median age of 16 , roughly equally distributed across grade 7 $(25.8 \%)$, grade $8(24.7 \%)$, grade $10(22.5 \%)$ and grade $11(26.9 \%)$.

\subsection{School staff results}

Scale scores by intervention group and time point are reported in Table 1. At baseline, most notable were relatively poor mental health knowledge, low levels of willingness to interact with people with mental illness, and relatively high levels of beliefs about mental illness as more negative perceptions of the dangerousness and incurability of mental disorders. Examining associations between baseline scale scores and demographics (sex, work experience, and level of education), the only positive association observed was between education and the total BMI score; relative to those with lower education, those with higher education had a more positive attitude toward mental illness $[\mathrm{F}(1,61)=4.093, \mathrm{p}=.047]$.

T-tests show significant within-group improvements in the intervention group for all variables except MHLS Recognition and MHLS Self-efficacy, for which observed improvements did not reach statistical significance. No significant within-group changes were observed among the control group. In the ANCOVA models, all four dependent variables from the Mental Health Literacy Scale were significantly different between the two groups at follow-up, with Recognition $\mathrm{F}(1,64)=5.17$, p $<.05$, Self-efficacy in help-seeking $\mathrm{F}(1,64)=5.09$, $\mathrm{p}<.05$, Stigma $\mathrm{F}(1,64)=6.24, \mathrm{p}<.05$, and Willingness to Interact $\mathrm{F}(1,64)=30.00, \quad \mathrm{p}<.0001$. In all instances, results favored the experimental group, with higher levels of recognition, selfefficacy, and willingness to interact, and lower levels of stigma (see Table 2). For the Beliefs about Mental Illness (BMI) scale, all three subscales showed significant Group effects, with BMI Dangerousness $\mathrm{F}(1,64)=17.47$, $\mathrm{p}<.0001$, BMI Poor skills $\mathrm{F}(1,64)=8.99$, $\mathrm{p}<0.005$, and BMI Incurable $\mathrm{F}(1,64)=7.91$, $\mathrm{p}<0.01$. All effects favored the experimental group, which showed lower levels of all variables at follow-up (Table 2). For the Mental Health Knowledge Quiz (MHK-Q) scale showed significant Group effects $F(1,64)=$ $22.22, \mathrm{p}<0.07$. Results favored the experiment group, with higher levels of mental knowledge (see Table 2).

\subsection{Student results}

Students reported low mental health knowledge and high levels of stigma at baseline (Table 1). At baseline, result showed no significant association between student sex and either knowledge or attitudes (both $p>.05$ ). Grade level was also not associated with knowledge $(p=.160)$, but upper secondary students did have a significantly higher attitude score than lower secondary students (4.13 vs. 3.73, $p<.001)$.

For the students who received the MHL curriculum, significantly higher levels of mental health literacy knowledge at follow-up were found as compared to the control group, $\mathrm{F}(1,272)=23.09, \mathrm{p}<.0001$. The students who received the MHL curriculum also showed significantly lower levels of stigma than the control group at follow-up, with F $(1,272)$ $=41.53, \quad \mathrm{p}<0.0001 \quad$ (see Table 2). No within-group changes were observed among control students, whereas intervention students showed small but significant improvements in both Knowledge and Stigma (Table 1).

\section{Discussion}

Knowledge, attitudes and beliefs about mental illness plays an important role in early identification and referral of children in need of support. In this regard, this preliminary study was conducted to investigate the knowledge, attitudes and beliefs and to assess the feasibility of a mental health literacy program, The Guide [38], on knowledge, beliefs and attitudes among teachers and students in Cambodia. Findings suggest that with limited adaptations to the original curriculum guide, a 2-day teacher 
mental health literacy training followed by teacher-led classroom implementation can improve teacher and student mental health literacy (i.e. knowledge, beliefs, and attitudes). This demonstrates the potential of sustainable approach aimed at training educators on the low-cost application and teacher-optimized resource and embedding the mental health literacy program into existing standard curriculum in classroom.

To our knowledge, this is the first study assessing teacher and student mental health literacy in Cambodia. Baseline results demonstrated that both teachers and students have limited knowledge, prejudiced perceptions and negative attitudes about mental illness. Baseline result showed consistent finding between teachers and students, teacher with high education background and student's grade had less negative beliefs and attitudes toward mental illness. Knowledge might be one of important factors to decrease stigma. As the previous report showed the public has very limited knowledge about mental health [33]. Culture might also be another main contributing factor to stigma around mental illness. Living in a culture that was mixed with various religious beliefs might bring more stigmatizing beliefs and attitudes. Khmer believe in Buddhist-Hindu beliefs, beliefs in spirits, luck and astrology, and emphasis on the connection between physical and mental health; help-seeking through the medical system often only occurs when traditional methods are unsuccessful in addressing the problem [15] .

Our findings are consistent with prior research in Vietnam using the same instruments, which showed Vietnamese teachers had poor knowledge of mental health problems[48]. Previous studies have also showed teachers had difficulty to identify and distinguish the severity of mental disorders, which reflects poor mental health literacy among teachers [49, 50]. Further, research across multiple settings such as United States, Canada, Malaysia and Nigeria have all demonstrated a need to improve students' knowledge, awareness, recognition, and stigma as well [51-54]. These current findings provide critical information about mental health literacy challenges in a context that receives little attention on the mental health care system, and where the low mental health literacy creates substaintial barries to mental health care $[33,34,52]$.

Our second finding of this current study confirms the mental health literacy program The Guide was effective at increasing teachers and student's mental health literacy (knowledge, beliefs, and attitudes). The finding was supported by previous literature that underpinned the effectiveness of mental health literacy programs for training teachers [56-58]. The largest effects for teachers were reported on the scales measuring willingness to interact with people with mental illness and perceptions of dangerousness. We posit two explanations for this. First, greater understanding about mental illness (i.e., the cause and effect) might increase empathy toward people experiencing mental disorder. Specifically, providing a bio-psycho-social framework that includes a medical explanation of mental illness as a brain or neurobiological disease may reduce perceptions of a spiritual cause of mental illness that implies something evil or something one brings upon oneself by bad action. Prior research has also shown that people who view mental illness as a medical condition tend to hold less stigmatizing attitudes than people who viewed mental illness through neurobiological explanation or brain condition $[59,60]$. Second, both willingness to interact and perceptions of dangerousness may be linked to fear: fear either of social or spiritual contamination, or fear of direct physical harm. Both increased understanding of the cause of mental illness and increased awareness that most mentally ill people are not dangerous should decrease fear and increase willingness to interact. To the best of our knowledge, most generally the public have more stigmatizing attitude because they perceived inaccurate information about mental illness, and promoting accurate information about mental illess could reduce stigma, prejudice, and increase their positive interaction 
with people with mental illness. These findings of smaller effects in other domains do, however, highlight areas to focus on in further refinement of The Guide.

Likewise, although we observed statistically significant effects at the student level, their low scores - particularly in knowledge - indicate room for additional improvement. These findings are not atypical; a previous study of The Guide reported about 14\% improvement among students receiving the intervention [51], compared to about $12 \%$ in the current study. Although literature supports teacher MHL training as a good strategy to promote children mental health care in school system [51, 61] its effectiveness may vary based on the methodology and actual context [62-65]. Potential factors affecting student outcomes in the current study may include both implementation factors and cultural/contextual fit. Below we discuss a number of these potential factors.

Cascading Training Model. This program was implemented by general education teachers who received a 3-day training, which included only one day of implementation (train-thetrainers) training. This level of training, although a direct carry-over from the North American curriculum, may be insufficient to prepare relatively inexperienced Cambodian teachers to deliver the mental health lesson to students. We observed during the teacher training a gap in knowledge of mental health literacy in general (manifested also in their prepost Quiz scores) and skills to deliver classroom curriculum. Teachers had difficulty understanding the conceptual framework to deliver the classroom curriculum. Even in Canada, previous research has found that teachers needed more preparation when working with mental issue [66]. Other studies in Canada and Haiti also emphasized the necessity to extending the duration and number of training sessions to get better outcome of the training [67, 68]. Teachers also reported feeling stressed and lacking confidence, in need extra support from the trainer besides the training for their preparation and delivery classroom curriculum. This concern has been observed elsewhere as well [69, 70]. We believe providing additional supports like continuing professional development, supervision or consultation would improve both teacher and student outcomes. This is consistent with literature that suggests supervision is necessary to lead to behavioral change for learning and teaching processes [71, 72]. Similar findings among Canadian teachers have also showed that supervision was important during delivering curriculum in classroom [70].

Dose. Beyond the dosage issues described for the teachers above, one hour per week may be insufficient to deliver the content of the six modules in Cambodia, even though prior study had showed the curriculum guide need six hours of classroom time or 4-8 weeks intervention [43]. Since this curriculum was developed for Western students, additional implementation changes may be needed. For example, Cambodian students may have lower baseline mental health literacy, requiring more intervention exposure. Additionally, Cambodian classrooms may have a larger number of students than Canada or the US, requiring adjustment to the classroom environment to allow time for teacher-student interaction. For instance, each module should require two sessions (two hours), and given this extension may provide more interaction between teachers and students.

Lack of motivation (intrinsic and extrinsic) may also be a factor. Teachers play an important role to created friendly learning environment that allow students to seek knowledge as worthwhile and take ownership over their learning [73-75]. However, as observed, teachers not only had difficulty understanding the concepts and teaching process but also face stressors related to managing large classrooms. Students may have also paid less attention than their usual study because there were no performance requirements, like taking an exam or receiving a grade.

Cultural fit. Although the Guide required minimal adaptations and was further reviewed 
by a team of highly trained Cambodian psychologists, it is also possible that some of this decreased impact was due to the lack of specific cultural and contextual adaptations. For example, previous research in Cambodia has documented culturally distinct mental health syndrome presentations $[76,77]$ that were not incorporated into The Guide. It is possible that expanding The Guide content to address these types of syndromes as well may improve outcomes by addressing a more comprehensive cultural understanding of what constitutes mental illness.

\section{Strength and Limitations}

Strengths of this study include incorporating a randomized experimental design into a real-world implementation context, inclusion of both teaching and nonteaching staff, as well as the low dropout rate of participants. There are, however, some important limitations. First, we conducted this study only in one private school; it is unclear whether these findings would generalize to other schools in Cambodia. Second, because not all staff were subsequently engaged in curriculum delivery they received less training and may have been less motivated to fully learn the material and implement The Guide. The single-school design also presented barriers to randomization; the control group students who did not receive the intervention may have had interactions with teachers, non-teaching staff, and students who have received the training. Additionally, although the assessment tools had been previously validated in Vietnam and were piloted before use, they were not separately validated in Cambodia. Finally, due to resource constraints we were unable to conduct a longerterm follow-up to evaluate sustained programmatic impacts on knowledge and attitudes, and ultimately on behavior. Knowledge and attitudes are seen as intermediate outcomes conceptualized as leading to the ultimate goals, of increased identification of mental health need, connection to services, and ultimately improved functioning. Our current findings are promising and support more extensive evaluation of the MHL curriculum in Cambodia to include further adaptation and study of implementation features.

\section{Conclusions}

The current study demonstrated consistently positive, although varying in magnitude, improvements in knowledge and attitudes among teachers and students following implementation of a classroom-based mental health literacy program in Cambodia. Integrating school-based mental health program in school setting can be a path-way solution to build the significant needs for children and adolescents in limited resource settings like Cambodia and is increasingly a focus in LMIC $[12,78]$. The task-sharing approach that engage teachers to take responsible in promoting mental health rather than professional to implement the schoolwide mental health programming in accessibility of service and reducing stigma associated with seeking mental health care through health facilities [43, 79]. However, low levels of mental health literacy in many LMIC, including among professionals such as teachers, indicate a basic need to strengthen staff and student understanding of mental health, mental health disorders, and their treatments, to decrease stigma, and increase help-seeking.

\section{Funding}

This study was carried out for Ph.D. dissertation to complete the requirement of the study and it was funded by Vietnam National University, Hanoi (VNU) under project number QG.16.61 and by the U.S. National Institutes of Health grants from the Fogarty International Center D43-TW009089 and R21 TW008435.

The funders of this study had no role in study design, data collection, data analysis, data interpretation, or writing the report.

\section{Acknowledgements}

The authors thank all involved teachers and students for their participation in the study. 
Thank Sr.Teresa Tuale, principal of Don Bosco High School-Teuk Thla for her great support to this study. Thank to Father Kevin Conroy, Ph.D. for his emotional support. Thank to research assistants and colleagues for their time assisting the data collection, training, classroom observation and hence substantially contributing to this study were. Ms. Chanthorn Leang, M.A., Ms. Bunnary Be, M.A., Ms. Hong Naysim, M.A., Mr. Thea Soung, M.A., Mr. Plaktin, M.A., Mr. Sophearith Phul, M.A., Som Vireak, M.A., Dr. Vannarith Toun (psychiatrist).

\section{References}

[1] C. Kieling, H. Baker-Henningham, M. Belfer, et al, Child and adolescent mental health worldwide: Evidence for action, Lancet 378 (9801) (2011) 1515-1525. https://doi.org/10.1016/S01406736(11)60827-1.

[2] G. Schulte-Korne, Mental Health Problems in a School Setting in Children and Adolescents, Dtsch Arztebl Int 113 (2016) 183-190. https://doi.org/10.3238/arztebl.2016.0183

[3] WHO, Child and Adolescent Mental Health, https://www.who.int/mental_health/maternalchild/child_adolescent/en/, Published 2018 (Accessed July 13, 2019).

[4] P.Y. Collins, V. Patel, S.S. Joestl, D. March, T.R. Insel, AS. Daar, Grand challenges in global mental health, Nature 475 (2011) 27-30. papers3://publication/uuid/5C53B469-EA28466F-82A3-8A4480B9347C.

[5] N. Votruba, G. Thornicroft, Sustainable development goals and mental health: learnings from the contribution of the FundaMentalSDG global initiative, Glob Ment Heal 3 (e26) (2016) 1-6. https://doi.org/10.1017/gmh.2016.20.

[6] S. Malhotra, S.K. Padhy, Challenges in Providing Child and Adolescent Psychiatric Services in Low Resource Countries, Child Adolesc Psychiatr Clin N Am 24 (4) (2015) 777-797. https://doi.org/ 10.1016/j.chc.2015.06.007.

[7] N. Imran, A. Rahman, N. Chaudhry, A. Asif, World Health Organization "School Mental Health Manual" - based training for school teachers in Urban Lahore, Pakistan: Study protocol for a randomized controlled trial, Trials 19 (2018) 1-8. https://doi.org/10.1186/s13063018-2679-3.
[8] D. Juengsiragulwit, Opportunities and obstacles in child and adolescent mental health services in low- and middle-income countries: A review of the literature, WHO South-East Asia J Public Heal 4 (2) (2015) 110-122.

[9] D. O'Brien, K. Harvey, J. Howse, T. Reardon, C. Creswell, Barriers to managing child and adolescent mental health problems: A systematic review of primary care practitioners' perceptions, Br J Gen Pract. 66 (651) (2016) e693-e707. https://doi.org/10.3399/bjgp16X687061.

[10] M.M. Barry, A.M. Clarke, R. Jenkins, V.A. Patel, Systematic review of the effectiveness of mental health promotion interventions for young people in low and middle income countries. BMC Public Health $13 \quad$ (2013) 1-19. https://doi.org/10.1186/1471-2458-13-835.

[11] M.D. Weist, S. Kutcher, Y. Wei, School Mental Health: Global Challenges and Opportunities, Cambridge Univ Press, 2015, pp. 1-5.

[12] V. Patel, C. Kieling, P.K. Maulik, G. Divan, Improving access to care for children with mental disorders: a global perspective, Arch Dis Child 98 (5) (2013) 323-327. https://doi.org/10.1136/archdischild-2012-302079.

[13] Y. Wei, J.A. Hayden, S. Kutcher, A. Zygmunt, P. McGrath, The effectiveness of school mental health literacy programs to address knowledge, attitudes and help seeking among youth, Early Interv Psychiatry 7 (2) (2013) 109-121. https://doi.org/10.1111/eip.12010.

[14] National Institute of Statistics, Directorate General for Health, and ICF International 2015. Cambodia Demographic and Health Survey 2014. Phnom Penh, Cambodia, and Rockville, Maryland, USA: National Institute of Statistics, Directorate General for Health, and ICF International; 2014. www.nis.gov.kh.

[15] T. Schunert, S. Khann, S. Kao et al, Cambodian Mental Health Survey - Cambodian Mental Health Survey, Phnom Penh, 2012.

[16] B. Jegannathan, G. Kullgren, P. Deva, Mental health services in Cambodia, challenges and opportunities in a post-conflict setting, Asian J $\begin{array}{llll}\text { Psychiatr } & 13 & \text { (2015) } & \text { 75-80. }\end{array}$ https://doi.org/10.1016/j.ajp.2014.12.006.

[17] D.M. Seponski, C.J. Lahar, S. Khann, S. Kao, T. Schunert, Four decades following the Khmer rouge: sociodemographic factors impacting depression, anxiety and PTSD in Cambodia, J Ment Heal. 28 (2) (2019) 175-180. https://doi.org/10.1080/09638237.2018.1466039. 
[18] S. Olofsson, M.S. Sebastian, B. Jegannathan, Mental health in primary health care in a rural district of Cambodia: A situational analysis, Int $\mathbf{J}$ Ment Health Syst 12 (1) (2018) 1-13. https://doi.org/10.1186/s13033-018-0185-3.

[19] ASEAN Mental Health System, In: ASEAN Mental Health System ASEAN, Jakarta, ASEAN Secretariat, December 2016 Vol (2016) 18-34. https://doi.org/10.4135/9781412952569.n105.

[20] M. Fazel, V. Patel, S. Thomas, W. Tol, Mental health interventions in schools in low-income and middle-income countries, The Lancet Psychiatry 1 (5) (2014) 388-398. https://doi.org/10.1016/S2215-0366(14)70357-8.

[21] L. Murray, S. Dorsey, E. Lewandowski, Global Dissemination and Implementation of Child Evidence-Based Practices in Low Resources Countries, In: Beidas R, Kendall P, eds. Dissemination and Implementation of EvidenceBased Practices in Child and Adolescent Mental Health, Oxford: Oxford University Press, 2014.

[22] Y. Wei, S. Kutcher, International School Mental Health: Global Approaches, Global Challenges, and Global Opportunities, Child Adolesc Psychiatr Clin N Am. 21 (1) (2012) 11-27. https://doi.org/10.1016/j.chc.2011.09.005.

[23] B. Weiss, V.K. Ngo, H.M. Dang et al, A model for sustainable development of child mental health infrastructure in the lmic world: Vietnam as a case example, Int Perspect Psychol Res Pract $\begin{array}{lllll}\text { Consult. } & 1 & \text { (1) } \quad \text { (2012) 63-77. }\end{array}$ https://doi.org/10.1037/a0027316.

[24] M.D. Weist, Challenges and opportunities in moving toward a public health approach in school mental health, J Sch Psychol. 41 (1) (2003) 77-82. https://doi.org/10.1016/S0022-4405(02)00146-2.

[25] W.M. Reinke, M. Stormont, K.C. Herman, R. Puri, N. Goel, Supporting children's mental health in schools: Teacher perceptions of needs, roles, and barriers, Sch Psychol Q. 26 (1) (2011) 1-13. https://doi.org/10.1037/a0022714.

[26] H.M. Dang, B. Weiss, C.M. Nguyen, N. Tran, A. Pollack, Vietnam as a case example of schoolbased mental health services in low and middle income countries: Efficacy and effects of risk status, Sch Psychol Int. 38 (1) (2017) 22-41. https://doi.org/10.1177/0143034316685595.

[27] Ministry of Planning, Cambodia Socio-Economic Survey, 2015.

[28] Literacy Target of a Sustainable Development Goal. https://www.phnompenhpost.com/opinion/literacy -target-sustainable-development-goal. Published 2017. Accessed July 15, 2019.

[29] A.F. Jorm, Mental health literacy, Public knowledge and beliefs about mental disorders, $\mathrm{Br}$ J Psychiatry. 177 (2000) 396-401.

[30] S. Kutcher, Y. Wei, C. Coniglio, Mental Health Literacy, Can J Psychiatry. 61 (3) (2016) 154-158. https://doi.org/10.1177/0706743715616609.

[31] K.A. Ganasen, S. Parker, C.J. Hugo, D.J. Stein, R.A. Emsley, S. Seeda, Mental health literacy: focus on developing countries, Afr J Psychiatry. $11 \quad$ (1) (2008) 23-28. https://doi.org/10.4314/ajpsy.v11i1.30251.

[32] F. Mascayano, J.E. Armijo, L.H. Yang, Addressing stigma relating to mental illness in low - and middle-income countries, Front Psychiatry $6 \quad$ (1) (2015) 1-4. https://doi.org/10.3389/fpsyt.2015.00038.

[33] TPO Cambodia, The Need for Mental Health Care in Cambodia. https://tpocambodia.org/the-need/, Published 2015 (Accessed July 14, 2019).

[34] S. Yamaguchi, J.C. Foo, A. Nishida, S. Ogawa, F. Togo, T. Sasaki, Mental health literacy programs for school teachers: A systematic review and narrative synthesis, Early Interv Psychiatry Vol (2019) 1-12. https://doi.org/10.1111/eip.12793.

[35] M. Anderson, A. Werner-Seidler, C. King, A. Gayed, S.B. Harvey, B. O'Dea, Mental Health Training Programs for Secondary School Teachers: A Systematic Review, School Ment Health Vol (2018) 1-20. https://doi.org/10.1007/s12310-018-9291-2.

[36] S. Eshun, R.A.R. Gurung, Culture and Mental Health: Sociocultural Influences, Theory, and Practice, Wiley-Blackwell, 2009.

[37] F.F. Marsiglia, J.M. Booth, Cultural Adaptation of Interventions in Real Practice Settings, Res Soc Work Pract $25 \quad$ (4) (2015) 423-432. https://doi.org/10.1177/1049731514535989.

[38] S. Kutcher, Mental Health \& High School Curriculum Guide: Understanding Mental Health and Mental Illness, USA Edition: Washington State, 2016

[39] S. Kutcher, Y. Wei, A. McLuckie, L. Bullock, Educator mental health literacy: a programme evaluation of the teacher training education on the mental health \&amp; high school curriculum guide, Adv Sch Ment Health Promot. 6 (2) (2013) 83-93. https://doi.org/10.1080/1754730X.2013.784615.

[40] S. Kutcher, H. Gilberds, C. Morgan, R. Greene, K. Hamwaka, K. Perkins, Improving Malawian teachers' mental health knowledge and attitudes: 
an integrated school mental health literacy approach, Glob Ment Heal 2 (2015) 1-10 http://www.who.int/mental_health/evidence/atlas/ interactive_infographic_2015.pdf?ua=1.

[41] S. Kutcher, Y. Wei, H. Gilberds et al, The African Guide: One Year Impact and Outcomes from the Implementation of a School Mental Health Literacy Curriculum Resource in Tanzania, J Educ Train Stud. 5 (4) (2017) 64-73. https://doi.org/10.11114/jets.v5i4.2049.

[42] S. Kutcher, Y. Wei, H. Gilberds et al, A school mental health literacy curriculum resource training approach: effects on Tanzanian teachers' mental health knowledge, stigma and helpseeking efficacy, Int J Ment Health Syst 10 (1) (2016) 1-9. https://doi.org/10.1186/s13033-0160082-6.

[43] R. Milin, S. Kutcher, S.P. Lewis et al, Impact of a Mental Health Curriculum on Knowledge and Stigma Among High School Students: A Randomized Controlled Trial, J Am Acad Child Adolesc Psychiatry. 55 (5) (2016) 383-391.e1. https://doi.org/10.1016/j.jaac.2016.02.018.

[44] M. O'Connor, L. Casey, The Mental Health Literacy Scale (MHLS): A new scale-based measure of mental health literacy, Psychiatry Res. $229 \quad(1-2) \quad$ (2015) 511-516. https://doi.org/10.1016/j.psychres.2015.05.064.

[45] M. Hirai, G.A. Clum, Development, reliability, and validity of the beliefs toward mental illness scale, J Psychopathol Behav Assess. 22 (3) (200) 221-236. https://doi.org/10.1023/A:1007548432472.

[46] T. Schunert, S. Khann, S. Kaoet al, Cambodian Mental Health Survey, 2012.

[47] H.M. Dang, B. Weiss, T. Lam, H. Ho, Mental health literacy and intervention program adaptation in the internationalization of school psychology for Vietnam, Psychol Sch. 55 (8) (2018)

941-954. https://doi.org/10.1002/pits.22156.

[48] D.O. Aluh, O.F. Dim, C.G. Anene-Okeke, Mental health literacy among Nigerian teachers, AsiaPacific Psychiatry e12329(September) (2018) 1-5. https://doi.org/10.1111/appy.12329.

[49] S.I. Mendonsa Rohan Dilip, Mental Health Literacy among elementary school teachers in rural south India, Delhi Psychiatry J. 16 (2013) 362-367.

[50] A. Mcluckie, S. Kutcher, Y. Wei, C. Weaver, Sustained improvements in students' mental health literacy with use of a mental health curriculum in Canadian schools, BMC Psychiatry.
Vol (2014) 1-6. https://doi.org/10.1186/s12888014-0379-4.

[51] I.O. Jack-ide, B.P. Azebri, K.E. Ongutubor, F.E. Amiegheme, Secondary School Students Awareness and Attitudes Towards Mental Health Disorders in Bayelsa State, Nigeria, Ann Behav Sci. $\quad 2 \quad$ (2) (2016) 1-5i. https://doi.org/10.21767/2471-7975.100022.

[52] O. Wahl, J. Susin, A. Lax, L. Kaplan, D. Zatina, Knowledge and Attitudes About Mental Illness: A Survey of Middle School Students, Psychiatr Serv. $\quad 63 \quad$ (7) (2012) 649-654. https://doi.org/10.1176/appi.ps.201100358.

[53] N.M.N. Mustafa, H. Habil, N.A. Ibrahim, H. Hassan, Awareness Level on Mental Illness Among Secondary School Students in Skudai, Johor, Psychol Behav Sci. 4 (5) (2015) 181-189. https://doi.org/10.11648/j.pbs.20150405.12.

[54] D. McLaughlin, E. Wickeri, Special ReportMental Health and Human Rights in Cambodia, 2012.

[55] S. Kutcher, Y. Wei, C. Morgan, Successful application of a Canadian mental health curriculum resource by usual classroom teachers in significantly and sustainably improving student mental health literacy, Can J Psychiatry. 60 (12) (2015) 580-586. https://doi.org/10.1177/070674371506001209.

[56] S. Kutcher, Y. Wei, C. Morgan, Successful Application of a Canadian Mental Health Curriculum Resource by Usual Classroom Teachers in Significantly and Sustainably Improving Student Mental Health Literacy, Can Jorunal Psychiatry 60 (12) (2015) 580-586.

[57] Y. Ojio, H. Yonehara, S. Taneichi et al, Effects of an Educational Program on Depression Literacy and Stigma Among Secondary School Students in Jazan City. Https://clinicaltrials.gov/show/nct02663180/, 2016:1-4. https://www.cochranelibrary.com/central/doi/10.1 002/central/CN-01595829/full.

[58] M.S. Lebowitz, W. Ahn, Effects of biological explanations for mental disorders on clinicians' empathy, Proc Natl Acad Sci. 111 (50) (2014) 17786-17790. https://doi.org/10.1073/pnas.1414058111.

[59] A. Loughman, N. Haslam, Neuroscientific explanations and the stigma of mental disorder: a meta-analytic study, Cogn Res Princ Implic. 3 (1) (2018) 1-12. https://doi.org/10.1186/s41235-0180136-1. 
[60] J. Whitley, J.D. Smith, T. Vaillancourt, Promoting Mental Health Literacy Among Educators: Critical in School-Based Prevention and Intervention, Can J Sch Psychol. 28 (1) (2013) 5670. https://doi.org/10.1177/0829573512468852.

[61] S. Kutcher, Y. Wei, A. McLuckie, L. Bullock, Educator mental health literacy: A programme evaluation of the teacher training education on the mental health \& high school curriculum guide, Adv Sch Ment Health Promot. 6 (2) (2013) 83-93. https://doi.org/10.1080/1754730X.2013.784615.

[62] S. Kutcher, A. Bagnell, Y. Wei, Mental health literacy in secondary schools: A Canadian approach, Child Adolesc Psychiatr Clin. http://www.sciencedirect.com/science/article/pii/S 1056499314001199/, 2015 (Accessed May 10, 2017).

[63] A. Mcluckie, S. Kutcher, Y. Wei, C. Weaver, Sustained improvements in students' mental health literacy with use of a mental health curriculum in Canadian schools, BMC Psychiatry. 14 (1) (2014) 1-7. https://doi.org/10.1186/s12888014-0379-4.

[64] Y. Wei, S. Kutcher, H. Hines, A. MacKay, Successfully Embedding Mental Health Literacy into Canadian Classroom Curriculum by Building on Existing Educator Competencies and School Structures: The Mental Health and High School Curriculum Guide for Secondary Schools in Nova Scotia, Lit Inf Comput Educ J. 5 (3) (2014) 1649-1654. https://doi.org/10.20533/licej.2040.2589.2014.0220.

[65] A.L. Andrews, Ready set ready yet? teacher readiness in dealing with mental health issues, Publ Herit Branch, 2012.

[66] S. Kutcher, H. Gilberds, M. Udedi, K. Perkins, Malawi Educators' Assessment of Student Mental Health Outcomes, Int Jorunal Sch an Cogn Psychol. 2 (009) (2015) 15-16. https://doi.org/10.4172/2469-9837.S2-009.

[67] E. Eustache, M.E. Gerbasi, M.C. Smith Fawzi et al, Mental health training for secondary school teachers in Haiti: a mixed methods, prospective, formative research study of feasibility, acceptability, and effectiveness in knowledge acquisition, Glob Ment Heal. 4 (2017) e4,1-16. https://doi.org/10.1017/gmh.2016.29.

[68] H.A. Udoba, Challenges Faced by Teachers when Teaching Learners with Developmental Disability.

https://www.duo.uio.no/bitstream/handle/10852/4 2438/Master-thesis-Humphrey-2-

2.pdf? sequence $=1 /, \quad 2014 \quad$ (accessed 24 September, 2018).
[69] T.D. Daniszewski, Teachers' Mental Health Literacy and Capacity towards Student Mental Health, Electron Thesis Diss Repos. https://ir.lib.uwo.ca/etd://ir.lib.uwo.ca/etd/1165/, 2013; ( accessed 23 April, 2019).

[70] Kikegbusi, N. Gloria, C.N. Eziamaka, The Impact of Supervision of Instruction on Teacher Effectiveness in Secondary Schools in Nigeria, Int Jorunal Adv Res Educ Technol. 3 (3) (2016) 405-407.

[71] A. Evans, A. Cody, A. Copeland et al, the Importance of Effective Supervision in, In: ANU Press. Vol (2017) 123-153. https://doi.org/10.2307/2960490.

[72] K.M. Valerio, Intrinsic motivation in the classroom, J Student Engagem Educ Matters. 2 (1) (2012) 30-35. https://doi.org/10.1053/crad.2001.0834 [doi].

[73] D. Blazar, A. Matthew, Kraft, Teacher and Teaching Effects on Students' Attitudes and Behaviors $\quad 39 \quad$ (2017) https://doi.org/10.3102/0162373716670260.Teach er.

[74] S. Bieg, S. Backes, W. Mittag, The role of intrinsic motivation for teaching, teachers' care and autonomy support in students ' Zur Rolle von intrinsischer Lehrmotivation

Lehrerfürsorglichkeit und Autonomieunterstützung für die selbstbestimmte Lernmotivation von Schülerinnen und Sc, J Educ Res Online. 3 (1) (2011) 122-140.

[75] D. Hinton, K. Um, P. Ba, Kyol Goeu ("Wind Overload") Part I: A Cultural Syndrome of Orthostatic Panic among Khmer Refugees, Transcult Psychiatry 38 (4) (2001) 403-432. https://doi.org/10.1177/136346150103800401.

[76] D.E. Hinton, M.H. Pollack, V. Pich, J.M. Fama, D.H. Barlow, Orthostatically induced panic attacks among cambodian refugees: Flashbacks, catastrophic cognitions, and associated psychopathology, Cogn Behav Pract. 12 (3) (2005) 301-311. https://doi.org/10.1016/S10777229(05)80052-5.

[77] C. Kieling, H. Baker-henningham, M. Belfer et al, Global Mental Health 2 Child and adolescent mental health worldwide : Evidence for action 378 (2011) 1515-1526. https://doi.org/10.1016/S01406736(11)60827-1.

[78] H.M. Dang, B. Weiss, C.M. Nguyen, N. Tran, A. Pollack, Vietnam as a case example of schoolbased mental health services in low and middle income countries: Efficacy and effects of risk status, Sch Psychol Int. 38 (1) (2017) 22-41. https://doi.org/10.1177/0143034316685595. 
Table 1

T1 and T2 mean (SD) scale scores by intervention group for Cambodian sample

\begin{tabular}{l|l|l|l|}
\hline Scale & Timepoint & Treatment & Control \\
\hline \multirow{2}{*}{ Teacher - MHLS Recognition } & $\mathrm{T} 1$ & $2.67(.50)$ & $2.41(.43)$ \\
\cline { 2 - 4 } & $\mathrm{T} 2$ & $2.74(.51)$ & $2.42(.40)$ \\
\hline \multirow{2}{*}{ Teacher - MHLS Self-efficacy } & $\mathrm{T} 1$ & $2.61(.71)$ & $2.50(.61)$ \\
\cline { 2 - 4 } & $\mathrm{T} 2$ & $2.74(.77)$ & $2.32(.67)$ \\
\hline \multirow{2}{*}{ Teacher - MHLS Stigma } & $\mathrm{T} 1$ & $1.72(.38)$ & $1.84(.48)$ \\
\cline { 2 - 4 } & $\mathrm{T} 2$ & $1.45(.64)^{* *}$ & $1.86(.62)$ \\
\hline \multirow{2}{*}{ Teacher - MHLS Willingness to interact } & $\mathrm{T} 1$ & $2.09(.46)$ & $1.84(.49)$ \\
\cline { 2 - 4 } & $\mathrm{T} 2$ & $2.51(.46)^{* * * *}$ & $1.81(.48)$ \\
\hline \multirow{2}{*}{ Teacher - BMI Dangerous } & $\mathrm{T} 1$ & $2.75(.68)$ & $2.90(.79)$ \\
\cline { 2 - 4 } & $\mathrm{T} 2$ & $1.99(1.04)^{* * * *}$ & $2.93(.73)$ \\
\hline \multirow{2}{*}{ Teacher - BMI Poor skills } & $\mathrm{T} 1$ & $1.85(.71)$ & $2.36(.71)$ \\
\cline { 2 - 4 } & $\mathrm{T} 2$ & $1.44(.77)^{* * *}$ & $2.20(.68)$ \\
\hline \multirow{2}{*}{ Teacher - BMI Incurable } & $\mathrm{T} 1$ & $2.96(.74)$ & $2.87(.72)$ \\
\cline { 2 - 4 } & $\mathrm{T} 2$ & $2.55(.66)^{* *}$ & $2.91(.60)$ \\
\hline \multirow{2}{*}{ Teacher - MHK-Q } & $\mathrm{T} 1$ & $.526(.078)$ & $.539(.080)$ \\
\cline { 2 - 4 } & $\mathrm{T} 2$ & $.646(.144)$ & $.513(.070)$ \\
\hline \multirow{2}{*}{ Student - MHL Knowledge } & $\mathrm{T} 1$ & $0.57(.13)$ & $0.56(.13)$ \\
\cline { 2 - 4 } & $\mathrm{T} 2$ & $0.61(.14)^{* * *}$ & $0.54(.12)$ \\
\hline \multirow{2}{*}{ Student - Stigma } & $\mathrm{T} 1$ & $4.05(.69)$ & $4.10(.86)$ \\
\cline { 2 - 4 } & $\mathrm{T} 2$ & $3.39(.84)^{* * * *}$ & $4.02(.77)$ \\
\hline
\end{tabular}

Notes. ${ }^{1}=$ Range of the MHLS scales is 0 ("strongly disagree") to 4 ("strongly agree"); range of BMI scales is 0 ("completely disagree") to 4 ("completely agree"). Student - MHL Knowledge is proportion correct. Range of the Student - Stigma scale is 0 ("strongly disagree") to 6 ("strongly agree"); Means are adjusted for T1 scores. ${ }^{*}=\mathrm{p}<.05,{ }^{* *}=\mathrm{p}<.01,{ }^{* * *}=\mathrm{p}<.001,{ }^{* * * *}=\mathrm{p}<.0001$ for within-group T1 to T2 comparisons

Table 2. Results of inferential analyses for Cambodian sample

\begin{tabular}{|c|c|c|c|c|}
\hline Dependent variable & $\begin{array}{l}\text { F test, for effect } \\
\text { of Group }\end{array}$ & $\mathbf{E S}^{1}$ & $\begin{array}{l}\text { Adjusted }^{2} \\
\text { Mean (SD) Tx }\end{array}$ & $\begin{array}{l}\text { Adjusted }{ }^{2} \text { Mean } \\
\text { (SD) Cntl }\end{array}$ \\
\hline Teachers - MHLS Recognition & $\mathrm{F}(1,64)=5.17^{*}$ & $R^{2}=.07$ & $2.71(.51)$ & $2.45(.38)$ \\
\hline Teacher - MHLS Self-efficacy & $\mathrm{F}(1,64)=5.09^{*}$ & $R^{2}=.07$ & $2.71(.72)$ & $2.33(.64)$ \\
\hline Teacher - MHLS Stigma & $\mathrm{F}(1,64)=6.24^{*}$ & $R^{2}=.09$ & $1.46(.64)$ & $1.85(.62)$ \\
\hline Teacher - MHLS Willingness to interact & $\mathrm{F}(1,64)=30.00^{* * * *}$ & $R^{2}=.27$ & $2.47(.39)$ & $1.85(.49)$ \\
\hline Teacher-BMI Dangerous & $\mathrm{F}(1,64)=17.47^{* * * * *}$ & $R^{2}=.19$ & $2.01(.97)$ & $2.89(.71)$ \\
\hline Teacher - BMI Poor skills & $\mathrm{F}(1,64)=8.99^{* *}$ & $R^{2}=.08$ & $1.57(.67)$ & $2.06(.56)$ \\
\hline Teacher - BMI Incurable & $\mathrm{F}(1,64)=7.91^{* * *}$ & $R^{2}=.09$ & $2.53(.58)$ & $2.93(.56)$ \\
\hline Teacher-MHK-Q & $F(1,64)=22.22$ & .258 & $.646(.14)$ & $.513(.07)$ \\
\hline Student - MHL Knowledge & $\mathrm{F}(1,272)=23.09^{* * * * *}$ & $R^{2}=.07$ & $0.62(.13)$ & $0.54(.12)$ \\
\hline Student - Stigma & $\mathrm{F}(1,272)=41.53^{* * * * *}$ & $R^{2}=.13$ & $2.40(.82)$ & $3.01(.77)$ \\
\hline
\end{tabular}

Notes: ${ }^{1}=$ effect size is semi-partial eta-squared, controlling for $\mathrm{T} 1 \mathrm{dependent}$ variable.

${ }^{*}=\mathrm{p}<.05,{ }^{* *}=\mathrm{p}<.01,{ }^{* * *}=\mathrm{p}<.001,{ }^{* * * *}=\mathrm{p}<.0001$ 